\title{
Room Temperature Ferroelectric Mixture of Chiral and Achiral Thioesters
}

\author{
J.M. Czerwiec ${ }^{a, *}$, M. Ossowska-Chruściel ${ }^{b}$, J. Chruściel $^{b}$ And S. Wróbel ${ }^{a}$ \\ ${ }^{a}$ Institute of Physics, Jagiellonian University, Reymonta 4, 30-059 Kraków, Poland \\ ${ }^{b}$ Institute of Chemistry, University of Podlasie, 3-go Maja 54, 08-110 Siedlce, Poland
}

Dielectric properties of the mixture of two thioester compounds: 4-8-alkoxybenzoate-thiocarboxyl S-4-pentylphenyl (8OS5), (s)-4-(1-methylheptyloxy)biphenyl-4-thiocarboksyl 4-9-alkilphenyl (MHOBS9) are presented. The chiral compound exhibits nematic $\left(\mathrm{N}^{*}\right)$ and ferroelectric smectic $\mathrm{C}^{*}$ phase $\left(\mathrm{SmC}^{*}\right)$. The achiral compound shows N, SmA and monotropic SmC and SmB phases. the mixture of both compounds of 0.5 molar fraction shows $\mathrm{SmC}^{*}$ in the wider temperature range than pure MHOBS9. The mixture was studied using frequency domain dielectric spectroscopy. Dielectric measurements for the $\mathrm{SmC}^{*}$ phase of the mixture revealed Goldstone mode at higher frequencies and Maxwell-Wagner relaxation at low frequencies.

PACS numbers: 77.84.Nh, 78.15.+e, 64.70.M-

\section{Introduction}

In this paper a report is given on the dielectric and electro-optic properties of a mixture composed of two thioesters presented in Fig. 1. $80 \mathrm{OS} 5$ is achiral compound showing rich polymorphism. MHOBS9 is chiral compound displaying $\mathrm{N}^{*}$ and $\mathrm{SmC}^{*}$ phases.

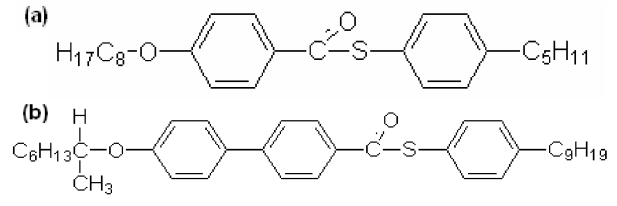

Fig. 1. Molecular structure for achiral 8OS5 (a) and chiral MHOBS9 (b) compounds.

TABLE I

Phase sequences for pure compounds and for their mixture.

\begin{tabular}{|c|c|c|}
\hline Acronym/run & Heating & Cooling \\
\hline $8 \mathrm{OS} 5$ & $\begin{array}{c}\mathrm{Cr} 58.9^{\circ} \mathrm{C} \mathrm{SmA} 65.8^{\circ} \mathrm{C} \mathrm{N} \\
85.5^{\circ} \mathrm{C} \mathrm{I}\end{array}$ & $\begin{array}{c}\mathrm{I} 85.5^{\circ} \mathrm{C} \mathrm{SmA} 67.4^{\circ} \mathrm{C} \mathrm{SmA} \\
50.9^{\circ} \mathrm{C} \mathrm{SmC} 31.3^{\circ} \mathrm{C} \mathrm{SmJ} 14.4^{\circ} \mathrm{C} \mathrm{Cr}\end{array}$ \\
\hline MHOBS9 & $\begin{array}{c}\mathrm{Cr} 93.9^{\circ} \mathrm{C} \mathrm{SmC}^{*} 106^{\circ} \mathrm{C} \mathrm{N}^{*} \\
122.8^{\circ} \mathrm{C} \mathrm{I}\end{array}$ & $\begin{array}{c}\mathrm{I} 122.5^{\circ} \mathrm{C} \mathrm{N}^{*} 105.8^{\circ} \mathrm{C} \mathrm{SmC}^{*} \\
84.8^{\circ} \mathrm{C} \mathrm{SmG} 46.4^{\circ} \mathrm{C} \mathrm{Cr}\end{array}$ \\
\hline 8OS5/MHOBS9 0.5 & $\begin{array}{c}\mathrm{Cr}_{1} 10.9^{\circ} \mathrm{C} \mathrm{Cr}_{2} 41.4^{\circ} \mathrm{C} \\
\mathrm{SmC}^{*} 80.7^{\circ} \mathrm{C} \mathrm{N}^{*} 105.7^{\circ} \mathrm{C} \mathrm{I}\end{array}$ & $\begin{array}{c}\text { I } 107.8^{\circ} \mathrm{C} \mathrm{N}^{*} 76.6^{\circ} \mathrm{C} \mathrm{SmC}^{*} \\
37.0{ }^{\circ} \mathrm{C}_{2} \mathrm{Cr}_{2} 9.1^{\circ} \mathrm{C} \mathrm{Cr}_{1}\end{array}$ \\
\hline
\end{tabular}

Both compounds are characterized in a few publications [1-6] but in this study 0.5 molar fraction mixture was made to obtain a ferroelectric phase at room temperature. Table I shows temperature range of each phase for pure compounds and for their mixture as well.

*corresponding author; e-mail: jan.czerwiec@uj.edu.pl

\section{Experimental}

Phase transitions were studied by means of differential scanning calorimetry (DSC) and texture observation. Transmitted light intensity (TLI) method was also applied to have better evidence of phase transitions in the mixture. Spontaneous polarization was measured by using reversal current method. 
Texture observation under AC field was done at the $\mathrm{N}^{*}-\mathrm{SmC} \mathrm{C}^{*}$ transition to observe the effect of monodomain growth. As seen in Fig. 2a-c upon temperature decrease in the vicinity of the $\mathrm{N}^{*}-\mathrm{SmC}^{*}$ transition the $\mathrm{SmC}^{*}$ phase aligns very well by $\mathrm{AC}$ field (Fig. 2c).
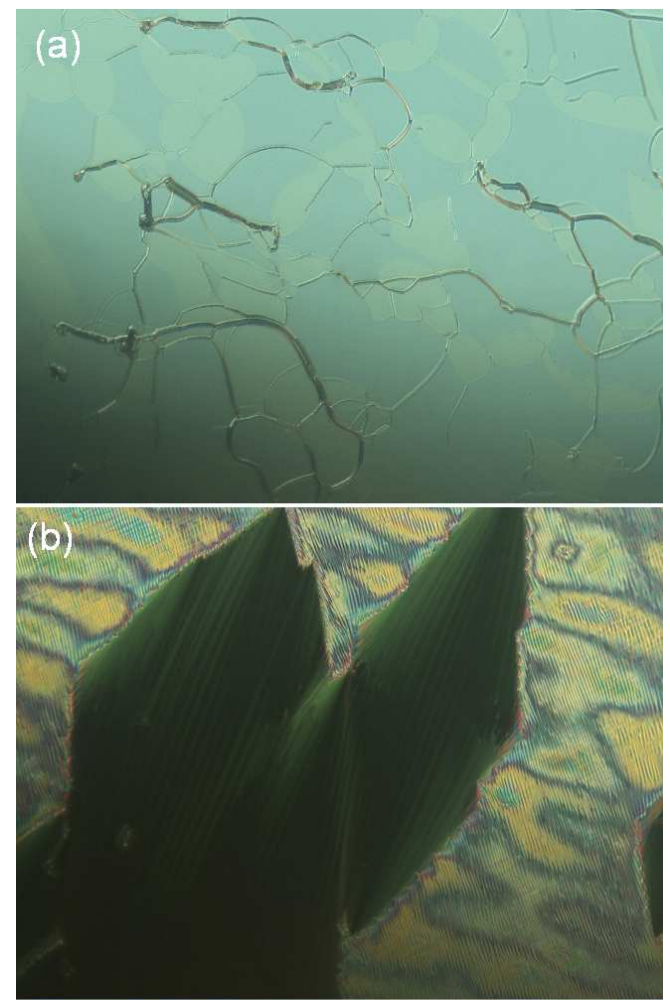

(c)

Fig. 2. Textures for mixture MHOBS9/8OS5.

(a) Cholesteric phase $\mathrm{N}^{*}\left(80^{\circ} \mathrm{C}, U=0 \mathrm{~V}_{\mathrm{p}-\mathrm{p}}, v=0 \mathrm{~Hz}\right)$. (b) Transition from $\mathrm{N}^{*}$ phase to $\mathrm{SmC}^{*}$ phase $\left(78.8^{\circ} \mathrm{C}\right.$, under electric voltage $U=70 \mathrm{~V}_{\mathrm{p}-\mathrm{p}}, v=1 \mathrm{~Hz}$ ). In the centre domain growing is revealed. (c) Aligned $\mathrm{SmC}^{*}$ $\left(77.3^{\circ} \mathrm{C}, U=100 \mathrm{~V}_{\mathrm{p}-\mathrm{p}}, v=1 \mathrm{~Hz}\right)$.

Spontaneous polarization using ITO $5 \mu \mathrm{m}$ cell was measured by reversal current method for the $\mathrm{SmC}^{*}$ phase. Figure 3a presents the reversal current spectrum of the mixture. As seen, the mixture exhibits a ferroelectric phase. $P_{\mathrm{s}}$ vs. temperature is depicted in Fig. $3 \mathrm{~b}$. The $\mathrm{N}^{*}-\mathrm{SmC}^{*}$ transition seems to be of the second order type because is showing continuous change of $P_{\mathrm{s}}$ close to $T_{\mathrm{c}}$. However, by fitting the mean field function: $P_{\mathrm{s}}=P_{0}\left(T_{\mathrm{c}}-T\right)^{\beta}$ to the experimental points one obtains the $\beta$ parameter equal to 0.31 which is characteristic for tricritical point. It is known from the studies on single component systems that the $\mathrm{SmC}^{*}-\mathrm{N}^{*}$ transition is of the first order type $[4,5]$.

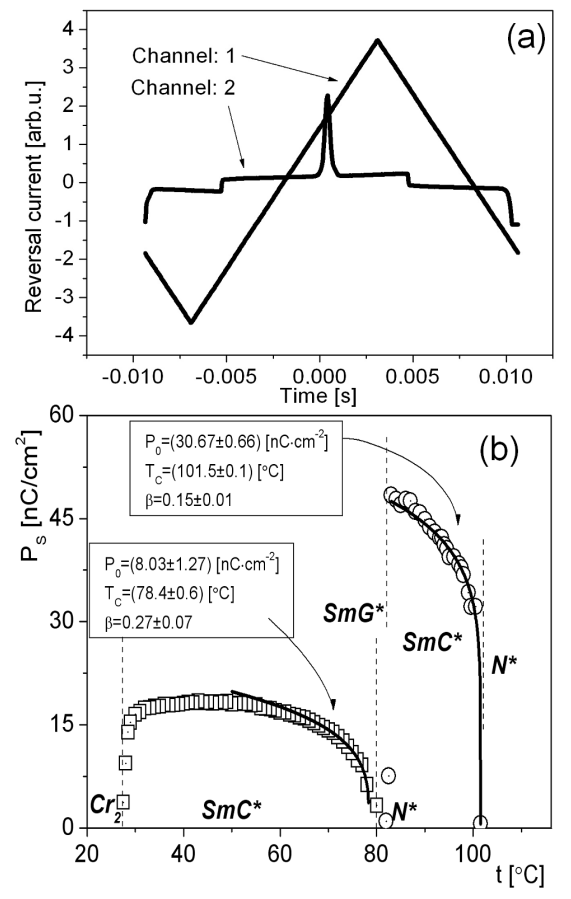

Fig. 3. (a) Reversal current spectrum (left scale) of $\mathrm{SmC}^{*}$ phase and triangular driving voltage. (b) $P_{\mathrm{S}}$ in $\mathrm{SmC}^{*}$ phase for MHOBS9/8OS5 mixture and for pure MHOBS9 compound.

Phase transition for the mixture studied were also observed by TLI method that consists in recording light transition by the electrooptic cell (Fig. 4).

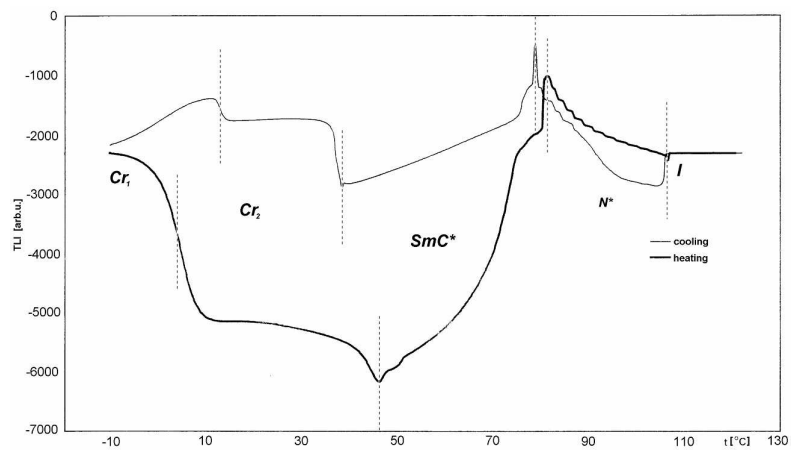

Fig. 4. TLI data vs. temperature cooling and heating diagram for MHOBS9/8OS5 0.5.

Dielectric measurements were performed using Agilent $4294 \mathrm{~A}$ impedance analyzer connected to gold planar $5.3 \mu \mathrm{m}(\mathrm{Au}-\mathrm{HG})$ cell. Complex dielectric permittivity was measured in the frequency range from $40 \mathrm{~Hz}$ 
to $10 \mathrm{MHz}$. Temperature was controlled by Eurotherm 2604. The value of measuring voltage was equal to $0.1 \mathrm{~V}_{\mathrm{RMS}}$. The mixture investigated was made in the Institute of Chemistry of the University of Podlasie, Siedlce, Poland.

\section{Results and discussion}

The dielectric spectra were measured on cooling of the sample. A Cole-Cole function with conductivity term (Eq. (1)) and with two relaxation processes for $\mathrm{SmC}^{*}$ phase was fitted to the experimental data

$$
\begin{aligned}
& \varepsilon_{\perp}^{*}(\nu)=\varepsilon_{\perp}^{\prime}-\mathrm{i} \varepsilon_{\perp}^{\prime \prime}=\varepsilon_{\perp}(\infty)+\sum_{k=1}^{2} \frac{\Delta \varepsilon_{\perp k}}{1+\left(\mathrm{i} \frac{\nu}{\nu_{\mathrm{R} k}}\right)^{1-\alpha_{k}}} \\
& \quad-\mathrm{i} \frac{\sigma}{\varepsilon_{0} 2 \pi \nu}, \\
& \tau_{\mathrm{R} k}=\frac{1}{2 \pi \nu_{\mathrm{R} k}}, \\
& \Delta \varepsilon_{\perp k}=\varepsilon_{\perp}(0)-\varepsilon_{\perp}(\infty)
\end{aligned}
$$

where $\nu$ is frequency, $\nu_{\mathrm{R} k}$ - relaxation frequency for $k$-th process, $\varepsilon_{\perp}(\infty)$ - electric permittivity in high frequency, $\varepsilon_{\perp}(0)$ - static electric permittivity, $\varepsilon_{0}$ - electric permittivity in free space, $\alpha$ - distribution parameter of relaxation time, and $\sigma-$ ionic conductivity. Dielectric parameters obtained are gathered in Table II.

TABLE II

Dielectric parameters obtained by fitting Eq. (1) to experimental data.

\begin{tabular}{c|c|c}
\hline \hline \multirow{2}{*}{} & \multicolumn{2}{|c}{$\mathrm{SmC}^{*}$} \\
\cline { 2 - 3 } & $\mathrm{MW}$ & $\mathrm{GM}$ \\
\hline$\Delta \varepsilon$ & $14.86 \pm 0.10$ & $15.21 \pm 0.10$ \\
\hline$\nu_{\mathrm{R}}$ & $193.68 \pm 6.36 \mathrm{~Hz}$ & $949.23 \pm 8.01 \mathrm{~Hz}$ \\
\hline$\alpha$ & $0.27 \pm 0.01$ & $0.01 \pm 0.01$ \\
\hline$\varepsilon(\infty)$ & \multicolumn{2}{|c}{$3.33 \pm 0.01$} \\
\hline$\sigma$ & \multicolumn{2}{|c}{$(1.09 \pm 0.02) \times 10^{-8} \mathrm{~S} / \mathrm{m}$}
\end{tabular}

Figures 5 and 6 present the dielectric spectra obtained without bias voltage and under DC bias voltage of 5 and $10 \mathrm{~V}$, respectively. As seen in the $\mathrm{SmC}^{*}$ phase, there are two low frequency dielectric relaxation processes: Maxwell-Wagner (MW) relaxation and Goldstone mode (GM). It is interesting to note that both these processes are being suppressed (Fig. 6) under bias field applied. As seen, the conductivity increases with bias field which means that unwinding the helix causes the enhancement of conductivity.

The relaxation frequency of GM mode (Fig. 5b) is practically constant within the $\mathrm{SmC}^{*}$ phase. The MaxwellWagner relaxation is due to anisotropy of the dielectric permittivity and conductivity. The relaxation time of MW relaxation increases with temperature as it is predicted by the model in which $\tau_{\mathrm{MW}}=\varepsilon_{2}^{\prime} / \kappa \sigma_{1}$ [7], where $\sigma_{1}$
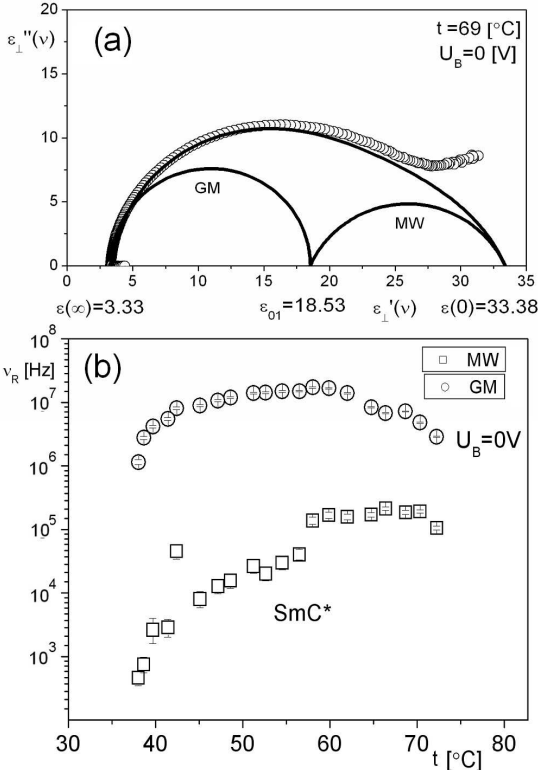

Fig. 5. Cole-Cole diagram for mixture MHOBS9/ 8 OS5 and (b) dielectric relaxation times frequency vs. temperature in the $\mathrm{SmC}^{*}$ phase: Maxwell-Wagner relaxation in the low frequency range and GM at higher frequencies.

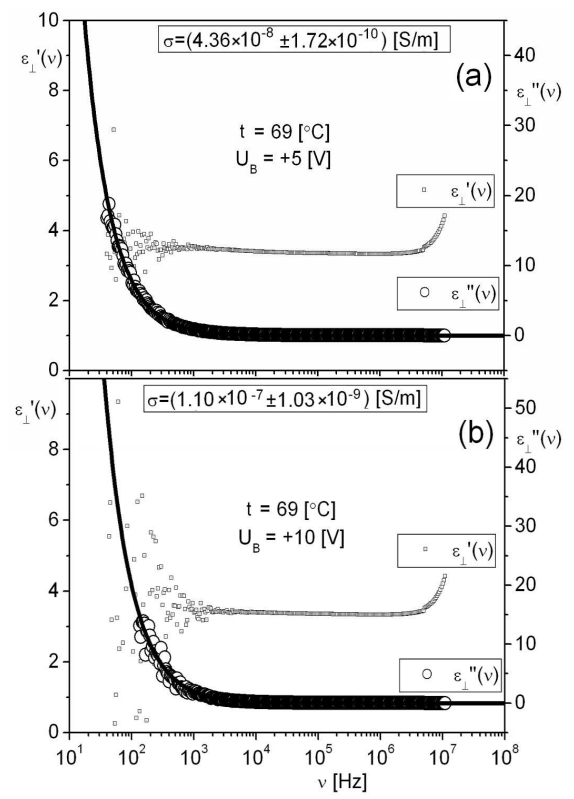

Fig. 6. Dielectric spectra of the mixture MHOBS9/8OS5 measured under bias voltages: (a) $5 \mathrm{~V}$ and (b) $10 \mathrm{~V}$.

is conductivity of liquid crystal layer, $\varepsilon_{2}^{\prime}$ - the dielectric permittivity of buffered polymer layer of the capacitor. $\kappa=x / d$, where in turn $x$ is the thickness of polymer layer and $d$ is the distance between the electrodes.

The dielectric increments $\Delta \varepsilon$ of both processes are comparable and equal to ca. 14. The Goldstone mode 
is a Debye-type spectrum whereas MW relaxation shows distribution of the relaxation times $\left(\alpha_{2}=0.27\right)$. As seen (Fig. 5b), GM and MW relaxation are non-Arrhenius processes.

\section{Conclusions}

Dielectric measurements show that there are two relaxation processes in the $\mathrm{SmC}^{*}$ phase of the mixture MHOBS9/8OS5, namely, GM and MW relaxation. The low frequency relaxation is caused by the conductivity anisotropy and dielectric anisotropy of the mixture. It was found that both processes can be suppressed under bias field.

Ferroelectric $\mathrm{SmC}^{*}$ aligns well in external AC field so that macroscopic monodomains can be grown for MHOBS9/8OS5 ferroelectric mixture which is important for practical applications.

\section{References}

[1] J. Chruściel, F.J. Bormuth, W. Hasse, S. Wróbel, Mol. Cryst. Liq. Cryst. 192, 95 (1990).

[2] J. Chruściel, S. Wróbel, B. Gestblom, W. Haase, in: Modern Topics in Liquid Crystals, Ed. A. Buka, World Sci., Singapore 1993.
[3] A. Mikułko, M. Marzec, M.D. Ossowska-Chruściel, J. Chruściel, S. Wróbel, Ferroelectric 343, 209 (2006).

[4] D.M. Ossowska-Chruściel, K. Kudłacz, A. Mikułko, J. Chruściel, R. Douali, M. Marzec, Ch. Legrand, A. Sikorska, S. Wrobel, Phase Transit. 80, 781 (2007).

[5] M. Marzec, J. Jankowski, I. Sowa-Pawłowski, W. Haase, S. Hiller, M. Pfeiffer, J. Oleszkiewicz, S. Wróbel, Nukleonika 39, 85 (1994).

[6] S. Wróbel, G. Cohen, D. Davidov, W. Haase, M. Marzec, M. Pfeiffer, Ferroelectrics 166, 211 (1995).

[7] Relaxation Phenomena, Liquid Crystals, Magnetic Systems, Polymers, High-T $T_{\mathrm{c}}$ Superconductors, Metallic Glasses, Eds. W. Haase, S. Wróbel, Springer-Verlag, Heidelberg 2003. 